\title{
Human Dimensions: Integrating the Social and Behavioral Sciences with the Biophysical and Natural Sciences
}

\author{
Prem Paul, Vice Chancellor for Research and Economic Development \\ Monica M. Norby, Assistant Vice Chancellor for Research \\ University of Nebraska-Lincoln, Lincoln, NE
}

s the needs and challenges of our societies become increasingly complex and
interrelated, so has the research required to generate solutions to these chal-
lenges. The last two decades have seen a growing emphasis on interdisciplinary research as a way of addressing complex problems. Reports such as "Facilitating Interdisciplinary Research," published in 2004 by the National Academies of Sciences and Engineering and Institute of Medicine of the National Academies stimulated discussion and efforts to break down barriers among disciplines. The National Science Foundation led the way in encouraging and even requiring interdisciplinarity in funded programs.

NSF's Integrated Graduate Education Research and Training (IGERT) program, competitions such as Science and Technology Centers and Engineering Research Centers, and other programs throughout NSF increasingly have emphasized interdisciplinary teams. Yet often the resulting "interdisciplinarity" has been collaborations among faculty from closely related fields, such as physicists with chemists or mathematicians with computer scientists.

\section{Human Dimensions}

In the $21^{\text {st }}$ century, the growing specter of climate change and other environmental threats brought a new kind of interdisciplinarity to research: the human dimensions. Initially, human dimensions referred to the interrelationships of people and the environment, particularly with respect to environmental change. Human dimensions often concerned broad issues dealing with government policies or institutional responses to change, their impact on society and the response of people affected by change. The human dimensions of global climate change - how human social systems affect and react to change in natural systems - became a critical focus of climate change research. Expertise in the social and behavioral sciences, such as political science, law, economics, sociology and other disciplines was critical to this research.

The need to address the human dimensions of science became clear at the University of Nebraska-Lincoln through two major research initiatives over the last five years. Over several years we developed a significant partnership with the U.S. Geological Survey to address climate change in the Greater Platte River Basin, which stretches from the Rocky Mountains to the Missouri River and encompasses all of Nebraska and parts of Colorado, Wyoming and South Dakota. The impact of climate change on agricul- 
ture and the water supply was a key focus of the research framework developed through the initiative, so the impacts on the people of the region were of paramount importance. Thus the research must address the needs of stakeholder groups ranging from farmers, ranchers and urban dwellers to natural resource districts, water managers, NGOs, and policy- and decision-makers at all level of government. Sociologists, economists, psychologists, law and policy experts, and education and extension specialists made significant contributions to the research framework, addressing the human dimensions of climate change.

In 2008 the University of Nebraska launched the Water for Food initiative, with the goal of forming a research, education and policy analysis institute with a global reach that would address the critical challenge of growing more food using less water. This is one of the largest and most complex challenges facing our nation and the global community. It demands our best ideas and an interdisciplinary approach, not only to find ways to produce more food with limited water supplies but also to change human attitudes and behaviors that prevent us from using water efficiently. Nowhere are the human dimensions of research more important than in the issues of food and water security, which go directly to the sustainability of life on the planet.

In April, 2010 the University of $\mathrm{Ne}$ braska was fortunate to receive a $\$ 50$ million founding gift commitment from the Robert B. Daugherty Charitable Foundation to support the global Water for Food Institute, now re-named the Robert B. Daugherty Water for Food Institute. Policy analysis, along with re- search and education, is one of the three focus areas of the WFI. All facets of the Institute's work must address the human dimensions. Law, economics, psychology, sociology, political science and other social and behavioral science are playing an important role in the Institute's work. It is an amazing opportunity to bring together faculty from many disciplines to create innovative programs that address a global need.

The expanding definition of human dimensions. Today the definition of human dimensions has expanded to include social and behavioral science research in fields beyond the natural sciences. The Department of Defense funds work in the human dimensions of military operations and of strategic leadership. Human dimensions have become an important topic in nanotechnology and nanoscience, because of societal fears of health threats from new materials. Human dimensions or human factors are important areas of research in fields as diverse as computer science and transportation engineering. This emphasis on human dimensions offers important new opportunities in social and behavioral science research and is leading to creative research approaches to many of our most complex societal challenges.

The Importance of Social and Behavioral Sciences Research

The social and behavioral sciences play a critical role in the intellectual life of the university and the research enterprise. The stature of every major university is measured in part by the strength of these disciplines, and research and scholarship in these sciences is an important driver of excellence in teaching 
and the training of the next generation of scholars. Research in these disciplines is critically important in meeting major challenges facing our society in education, national security, human health and well-being, food and water security, climate change and other areas.

Despite the need for this research, funding from the federal agencies for these disciplines (with the exception of education) has lagged far behind that available for engineering and the physical and biomedical sciences. This is beginning to change, driven in part by the emphasis on the human dimensions of complex societal problems, in part by the need to push research out of the lab and into the larger society where it can contribute to potential solutions.

The Role of Social and Behavioral Research in National Initiatives

The National Science Foundation (NSF) and National Institutes of Health (NIH) are two examples of funding agencies where the social and behavioral sciences - and the human dimensions are being emphasized more and more. At NSF, each proposal received must address the broader impacts of the research. Two questions from the description of broader impacts are:

- Will results be disseminated broadly to enhance scientific and technological understanding?

- What may be the benefits of the proposed activity to society?

These two questions basically address the human dimensions of the research. How will research - in any field be communicated to and benefit society? This defines a key role for social and behavioral sciences in NSF competitions.
At NIH there is a similar emphasis on the dissemination and implementation of health research, aimed at closing the gap between experts and health care providers. The goal is to push the research out of the lab and into the hands of practitioners, where it can benefit society. Translational research is a priority at NIH. It focuses on improving patient access, reorganizing and coordinating systems of care, helping clinicians and patients to change behaviors and make informed choices and providing decision-support tools - the very definition of the human dimensions of research.

There are similar emphases now in many large-scale initiatives, which require significant educational, outreach and dissemination components that can best be addressed through the involvement of social and behavioral researchers. In today's intense competition for funding a proposal that does not address some aspect of human dimensions/social and behavioral research often will not be successful.

Support for Social and Behavioral Science Research at UNL

The past decade at UNL has seen a significant emphasis on engaging and supporting social and behavioral scientists. These activities include:

- Interdisciplinary retreats to establish relationships among diverse disciplines

- Internal grants competitions to create research clusters

- Bringing program officers from federal agencies and private foundations to campus

- $\quad$ Targeted hires 
- Extensive support for development of large-scale proposals

- Support for conferences, workshops

These activities are not unique, but we have pursued them consistently over many years and it has made a real difference in establishing strong research programs and building expertise in key areas. A few of these are described below.

Social and Behavioral Science Centers. Several well-established centers at UNL are based in social and behavioral science disciplines. These are highly successful centers that generate well-funded research within their fields. They also are important collaborators who add human dimensions research to proposals in engineering and the physical and biomedical sciences.

Nebraska Center for Research on Children, Youth, Families and Schools

This center conducts interdisciplinary research to promote the intellectual, behavioral, and socialemotional development and functioning of individuals. Areas of research include:

- Early childhood education and intervention

- Academic intervention, instruction and learning

- Youth risk, resilience and health promotion

National Center for Research on

\section{Rural Education}

The center's research contributes to data-based understandings of what works, for whom, and under what conditions in the rural context in the areas of instruction/education, professional de- velopment of teachers, and related issues.

\section{University of Nebraska Public} Policy Center

The Center provides the opportunity for policy makers and researchers to work together to address challenges of local, state, and federal policy. Center researchers come from diverse disciplines, including: Business, Economics, Family and Consumer Sciences, Law, Political Science, Psychology, and Sociology.

Center for Children, Families and the Law

This center is a home for interdisciplinary research, teaching, and public service on issues related to child and family policy and services. The knowledge generated and synthesized by the Center is widely disseminated to educate policy makers, scholars, service providers, and the general public.

Social and Behavioral Health Research. Listed below are highlights of a few UNL research projects, though many other researchers work in these areas.

Sexual Revictimization: Emotional and Psychosocial Mechanisms, Dr. Don DiLillo

A \$3.1 million grant from NICHD to study the processes by which childhood or adolescent victimization is linked to adult revictimization.

Alcohol Use in American Indian Adolescents; Causes of Homelessness in Women; Community-based Research on Racial/Ethnic Minority Populations; Dr. Les Whitbeck

Dr. Whitbeck is a national leader in research on ethnic and minority populations. 


\section{Bullying: Risk Factors and Conse- quences; Dr. Susan Swearer}

For more than a decade Dr. Swearer has been a leader in bullying research, which has suddenly gained prominence on the national agenda. She served on an expert panel at the 2011 White House Conference on Bullying Prevention.

\section{Human Trafficking}

This important international issue was brought to our attention by an interdisciplinary faculty team that includes journalism, law, economics, family and consumer sciences and psychology. They have received support for an annual conference and for a consultant to help with proposal development. It is an interest case study, because while the conferences have been very successful, finding funding for this work is extremely difficult - as is often the case in some areas of social and behavioral science research.

Integrating the Social and Behavioral Sciences with the Natural and Physical Sciences

An important element of our support for social and behavioral research at UNL has been our insistence on interdisciplinarity and the integration of those disciplines with the physical and natural sciences, where possible and where it makes sense.

For instance, retreats around key initiatives always emphasize the inclusion of social and behavioral science researchers as a way of connecting faculty and building potential partnerships. In giving internal support for large-scale science proposals we emphasize building in studies of the human dimensions that include researchers from education, policy, economics, psychology, sociology and other disciplines.
This has led to innovative ideas and initiatives, increased funding opportunities and more funded proposals for faculty in the social and behavioral sciences. Below are some examples of projects where we believe we have very successfully integrated the social and behavioral sciences with engineering and the biophysical and biomedical sciences.

Nanoscience and Human Dimensions. Nanotechnology is a field that is generating a great deal of discussion about potential risks and hazards. Many people who do not understand the science are fearful of what these new materials might mean in their lives. The UNL project NIRT: NanoManufacturing and Analysis of Active Hierarchical Nanofilamentary Nanostructures was funded by a \$1 million NSF grant. It includes a study that focuses on the perceived and real dangers of nanomaterials and their effect on research and public policy, and includes faculty from our Public Policy Center and College of Law. This is an example of how addressing the human dimensions of leading edge research may help to divert social concerns as the technology evolves.

Center for Brain Biology and Behavior. This is a newly proposed interdisciplinary center that brings together psychologists, political scientists, biologists and engineers to study brain concussion, human performance, and correlation of human behavior with genetics. This is also a unique collaboration between academics and athletics. The center has attracted a new talented colleague, Dennis Molfese, to the university who is a renowned brain expert and is providing leadership for this center. A new facility is being constructed in collaboration with 
the Department of Athletics to house this center. The university has made major investments in support of this new center including acquisition of whole body functional magnetic resonance imaging equipment. This collaboration has been received enthusiastically at the university.

Natural Science and Human Dimensions. A UNL IGERT project, "Resilience and Adaptive Government in Stressed Watersheds," addresses the scientific, socio-economic and legal aspects of managing and governing watersheds. It is training 26 doctoral students drawn from law, natural resources, political science and computer science, a truly interdisciplinary and human dimensions approach to the management of water resources.

Communicating Health Science. A UNL project called "World of Viruses," funded by a Science Education Partnership Award from NIH, is an exciting example of innovative ways to translate and communicate biomedical science to young people. "World of Viruses" began as a book, evolved into comic books, and apps for mobile phones and one of the very first apps for the iPad. Experts in virology, journalism, computer science and graphic design combined their skills to produce these award-winning products for health messaging to young people about HIV, HPV and influenza.

\section{Closing comments:}

Our experience in fostering interdisciplinary collaboration amongst social sciences, physical sciences life sciences research has met with some success. The major hurdle is lack of knowledge amongst faculty about mutual research interests and expertise. Interdisciplinary faculty retreats, bringing faculty from multiple disciplines together on special topics and seed funding for new collaborations have been helpful in forming successful teams. It is also critical that we as a nation support social and behavioral science research as disciplines to ensure research and scholarship in those disciplines is nurtured and scholars are available for the future. Demand for scholars in social and behavioral sciences that are equipped with skills and tools to deal with human dimensions is only going to increase as global society faces challenges in dealing with health, food security, national security, climate change and national competitiveness. 